\title{
Impact of heat treatment on microbiota of black soldier fly larvae reared on soybean
} \section{curd residues}

\author{
A.A. Soomro ${ }^{1}$, M. Cai ${ }^{1}$, Z.A. Laghari ${ }^{2,3}$, L. Zheng ${ }^{1}$, K. ur Rehman ${ }^{1,4}$, X. Xiao ${ }^{1}$, S. Hu ${ }^{5}$, Z. Yu ${ }^{1}$ and J. Zhang ${ }^{*}$ \\ ${ }^{1}$ State Key Laboratory of Agricultural Microbiology, National Engineering Research Center of Microbial Pesticides, College \\ of Life Science and Technology, Huazhong Agricultural University, Wuhan 430070, China P.R.; ${ }^{2}$ Institute of Hydrobiology, \\ Chinese Academy of Sciences, Wuhan, Hubei Province, 430072, China P.R.; ${ }^{3}$ Department of Veterinary Parasitology, Sindh \\ Agriculture University, Tandojam, Sindh, 70060, Pakistan; ${ }^{4}$ Livestock and Dairy Development Department, Poultry Research \\ Institute, Murree Road, 4600 Rawalpindi, Punjab, Pakistan; ${ }^{5}$ School of Biology and Pharmaceutical Engineering, Wuhan \\ Polytechnic University, Wuhan, Hubei 430023, China P.R.; zhangjb@mail.hzau.edu.cn
}

Received: 25 August 2020 / Accepted: 7 October 2020

(c) 2021 Wageningen Academic Publishers

OPEN ACCESS CC) (7) (2) RESEARCH ARTICLE

\begin{abstract}
Entomophagy has emerged as an alternative and viable source of high-quality animal-derived proteins and fats for livestock production or as a human food supplement. The use of black soldier fly larvae (BSFL) as a dietary protein source for animals needs to be hygienically safe. The authors analysed the microbial community structure of the BSFL raised on different diets and investigated the effect of various heat treatments on the bacterial composition through 16S rRNA gene amplicon pyrosequencing. The results revealed that the diet of BSFL could alter the bacterial community structure. However, there are substantial differences in the abundance or diversity of individual bacterial populations. The bacterial community was dominated by four common phyla, including Proteobacteria, Firmicutes, Bacteroidetes, and Actinobacteria. Most of the samples show the presence of some potential foodborne pathogens such as Bacillus, Aeromonas, Campylobacter, Pseudomonas, Proteus, Klebsiella, Helicobacter, and Enterococcus. Furthermore, looking at the microbial community structure of BSFL, the post-harvest heat treatment showed a significant effect on human pathogens when compared to those in the control group without heat treatment. Enterococcus in BSFL raised on soybean curd residues (SCR) diet disappeared after heat treatments in all groups. Moreover, Staphylococcus in BSFL raised on artificial feed (AF) diet disappeared after heat treatment. The heattreated samples of BSFL reared on SCR, and AF (Group OD22 samples dried in the oven for 22 minutes and at a temperature of $150^{\circ} \mathrm{C}$ ) had a better influence on the community structure as compared to all heat treatments. This study provides the baseline data on the microbial composition and potential pathogens of BSFL reared on different dietary sources and showed the effect of different heat treatments on the microbial community.
\end{abstract}

Keywords: edible insect, thermal processing, microbial community, pathogens

\section{Introduction}

Insects are colonized by various microorganisms, and with the development of next-generation sequencing (NGS) technologies, it is suggested that these symbiotic relationships have significant effects on host development, nutrition, and pathogen defence mechanisms (Chen et al., 2016; Sun et al., 2016).
The global population is expected to exceed 9 billion by 2050 (Lalander et al., 2019; Soomro et al., 2019). And that population will need more animal-based products (Delicato et al., 2020). Several studies have shown that entomophagy, i.e. consumption of edible insects and insect products, can replace conventional animal protein sources (Delicato et al., 2020; Oonincx and De Boer, 2012; Stoops et al., 2016). Insects are estimated to be the source of the traditional diet of nearly 2 billion people, primarily in Africa, Asia, and the Americas. However, consumer acceptance of edible 
insects in most Western industrialised countries is still limited by aversion, and the link is often made between edible insects and primitive behaviour (Van Huis, 2013; Verbeke, 2015). A large number of edible insects are rich in nutrients with a high quality of protein, adequate amount of lipids, vitamins, minerals (such as calcium, zinc, and iron) and fibre because of the existence of chitin (Belluco et al., 2013; Rumpold and Schlüter, 2013).

Soybean curd residue (SCR) is the main waste product of soybean after processing. BSFL has the capability to convert a variety of low-value organic waste products into insect biomass with high fat and protein (Cai et al., 2018a; Rehman et al., 2019; Soomro et al., 2019). BSFL are considered one of the most promising species in industrial feed production and recommended as a choice for conversion of organic waste worldwide by the Food and Agriculture Organization (FAO) of the United Nations (Cai et al., 2018b). Compared to traditional livestock, insects reproduce faster, convert feed to protein very efficiently, require less breeding space, and are responsible for fewer greenhouse gas and ammonia emissions (Klunder et al., 2012; Van Huis, 2013). A possible use of BSFL in the food sector has also been discovered, and insect meal could partially replace soy bean-meal and fish-meal as a source of protein in feed production.

The originality of food is a significant issue, as impure and fake foodstuff practices affect consumer confidence and the safety of food (Barnett et al., 2016; Haynes, 2019). In contrast to the nutritional characteristics of known edible insects, their food safety and shelf life have not been studied to date (Stoops et al., 2016). Hence, from this perspective, it is necessary to accurately and reliably identify the microbial population of edible insects to assess the possible presence of pathogens and useful microorganisms. To the best of our knowledge, so far, there has been scarce research on the microbiological characteristics of fresh and processed edible insects. Most of them are based on phenotypic methods for culture-dependent analysis and microbial identification (Hernández-Flores, 2015; Klunder et al., 2012; Opara et al., 2012). High throughput DNA sequencing, assisted by developments in sequencing technology (NGS), has altered many fields of biology, comprising medical microbiology, animal and plant genomics, and the study of gene transcription (Haynes et al., 2019). At present, the use of next-generation high-throughput sequencing technology enables an effective and far-reaching evaluation of the biodiversity in food, which has been used for cultureindependent research of food microbiota (Ercolini, 2013). Furthermore, to the best of the author's knowledge, as far as bacterial community analysis is concerned, there are only a few previous studies on fresh larvae samples for human consumption by pyrosequencing (Garofalo et al., 2017; Stoops et al., 2016).
Traditional processing methods, including heat and chemical treatments, are considered an effective step in reducing microbial loads in insects, while improving the digestibility of insects used as food material (Caparros Megido et al., 2018; Rumpold et al., 2014). However, the nutritive value of these insects can be negatively affected if extensive heat treatments are applied. Previous data indicate that different heat treatments and high pressure can significantly reduce the microbial counts in fly larvae without affecting nutritive value and digestibility of the larva (Campbell et al., 2020). However, heat treatments that aim to reduce microbial counts without structurally damaging insects are highly useful when insects are used as feed for animals in order to prevent diseases caused by the presence of pathogenic bacteria in larvae (Caparros Megido et al., 2018; Rumpold et al., 2014).

The thermal processing of food is an effective method of inactivating microorganisms for the purpose of ensuring the safety of food (Kubo et al., 2020). The use of different processing methods is one of the most commonly adopted strategies (Liavata et al., 2019). The quality of the product obtained depends largely on the methodology used. The adoption of dietary thermal processing drives human evolution and changes in the diversity of the gut microbiota in a manner dependent on dietary habit. At present, the style and amount of food consumed by modern-day humans are changing rapidly. There is increased consumption of heat-treated (such as cooked) or disinfected foods because of more effective absorption and prevention of infectious diseases (Zhang and Li, 2018). However, scientific research on possible safety risks associated with the consumption of edible insects like BSFL must be conducted for markets and consumers.

In this case, the microbiome of edible insects deserves to be investigated: that is, whether thermal processing can cause microbial variation in BSFL used as food. Therefore, this study focuses on the comparison of the relative microbiota of non-thermally processed (fresh) and thermally processed BSFL, and looks at the BSFL microbiota developed on two different substrates, SCR and AF, to monitor the influence on and symbiotic role of the microbial community in BSFL.

\section{Material and methods}

\section{Collection of BSFL and substrate}

BSFL were collected from a colony that has been nurtured at Huazhong Agricultural University (HZAU) for 12 years from a poultry house facility in Wuhan, China during November 2008 (Li et al., 2015; Zheng et al., 2012). BSFL were fed with SCR and fly larva from modified AF diet for six days (modified AF: $75 \mathrm{~g}$ corn flour, $75 \mathrm{~g}$ bran and 350 g water (Tomberlin et al., 2002)), before being used in 
the experiments. The SCR was obtained from the HZAU cafeteria.

\section{Experimental design and operation}

In the present study, BSFL were fed on two different substrates, i.e. SCR and AF.

A total of $500 \mathrm{~g}$ of each feed (calculated on dry matter) and 1000 randomly selected six-day-old BSFL were put into a three-litre plastic bucket. The experiment was conducted in triplicate at constant relative humidity of $70 \%$ and temperature $27{ }^{\circ} \mathrm{C}$ at the BSF Wuhan colony. When $1 \%$ of prepupae developed in each replicate bucket, the study was terminated. BSFL were removed manually from the residues using sterile forceps and were kept off feed for one day to clear their guts (Charlton et al., 2015). Afterwards, prior to the study, the BSFL were killed at $105^{\circ} \mathrm{C}$ for $5 \mathrm{~min}$ in the microwave oven (Rehman et al., 2017b), after which different thermal conditions were applied as follows:

- C: fresh BSFL samples (Control)

- FD: dried BSFL samples in the freeze-drying machine (48 hours at $-20{ }^{\circ} \mathrm{C}$ )

- MD10: heat the BSFL samples in the microwave oven $\left(10\right.$ minutes at $150{ }^{\circ} \mathrm{C}$ )

- OD22: dried samples in the oven $\left(22 \mathrm{~min}\right.$ at $150{ }^{\circ} \mathrm{C}$.)

- MD5: dried samples in the microwave $\left(5 \mathrm{~min}\right.$ at $\left.150^{\circ} \mathrm{C}\right)$.

- OD5: dried samples in oven $\left(5 \mathrm{~min}\right.$ at $\left.150{ }^{\circ} \mathrm{C}\right)$.

\section{Extraction of genome DNA}

A total of five BSFL from each group were selected and then ground. The total DNA of fresh and processed BSFL samples was extracted using a PowerSoil DNA Isolation Kit (MO BIO Laboratories, Carlsbad, CA, USA) adopting the manufacturer's protocol. Extracted DNA was kept at $-80{ }^{\circ} \mathrm{C}$ for community analysis of the microbiota. The DNA concentrations of each sample were determined by a Nanodrop 2000 Spectrophotometer (Thermo Fisher Scientific, Waltham, MA, USA). Real-time quantitative PCR was performed using SYBR green and a CFX384 Touch realtime PCR detection system (Bio-Rad, Hercules, CA, USA).

\section{S rDNA sequencing and real-time quantitative PCR amplification}

A total of 18 DNA samples from larvae were examined by sequencing the $\mathrm{V} 3+\mathrm{V} 4$ regions of the bacterial $16 \mathrm{~S}$ rRNA from Novogene Bioinformatics Technology Co., Ltd (Tianjin, China). Primer sets regions for the amplification reactions were 341F/806R, (341F ACTCCTACGGGAGGCAGCAG, 806R GGACTACHVGGGTWTCTAAT), and the amplicons were sequenced using an Illumina sequencing kit and an Illumina HiSeq 2500 PE 250 sequencer (Illumina, San Diego, CA, USA). The closed reference operational taxonomic unit (OTU) selection strategy was used to assign sequences with $97 \%$ similarity to the same OTU. The species annotation is based on GreenGenes Database (http://greengenes.lbl.gov/cgi-bin/nph-index.cgi). PCR amplification was performed on the Thermal cycler Gradient Thermo cycler (SensoQuest GmbH, Göttingen, Germany), using a total of $20 \mu \mathrm{l}$ reactions, including 1 $\mu \mathrm{l}$ of DNA template, $1 \times$ PCR buffer according to the manufacturer's protocol. Afterwards, the following cyclic parameters were used: initially, $5 \mathrm{~min}$ at $94{ }^{\circ} \mathrm{C}$, followed by 30 cycles at $94{ }^{\circ} \mathrm{C}$ for $30 \mathrm{~s}$, then at $56^{\circ} \mathrm{C}$ for $40 \mathrm{~s}$, and finally for extension time $10 \mathrm{~min}$ at $72{ }^{\circ} \mathrm{C}$.

The human pathogens list was obtained from the online database (http://www.mgc.ac.cn/VFs/main.htm) and compared with the present study. The Virulence Factor Database is a comprehensive and integrated online resource for collating data and information on the virulence factors of bacterial pathogens.

\section{Statistical analysis}

The univariate analysis of covariance was performed using SPSS 19.0 (SPSS Inc., Chicago, IL, USA). In addition, the standard deviation and averages of all data were processed using Microsoft Excel 2010 (Microsoft Corporation, Redmond, WA, USA).

\section{Results}

\section{Sequencing of microbiota}

We analysed 10 BSFL microbiota samples from two different groups of BSFL raised on diets of SCR or AF. We divided each group into six different categories according to the treatments: C, fresh sample; FD, dried BSFL samples in the freeze-drying machine ( 48 hours at $-20{ }^{\circ} \mathrm{C}$ ), MD10, heat the BSFL samples in the microwave $\left(10 \mathrm{~min}\right.$ at $\left.150{ }^{\circ} \mathrm{C}\right)$; OD22, dried samples in the oven $\left(22 \mathrm{~min}\right.$ at $\left.150^{\circ} \mathrm{C}\right)$, MD5, dried samples in the microwave $\left(5 \mathrm{~min}\right.$ at $\left.150{ }^{\circ} \mathrm{C}\right)$; and OD5 dried samples in oven $\left(5 \mathrm{~min}\right.$ at $\left.150^{\circ} \mathrm{C}\right) . \mathrm{C}$ represents fresh samples without any heat treatment used as controls, while others indicate that after sampling, the samples were processed used heat treatments. After the treatment process, all samples were further processed for $16 \mathrm{~S}$ rRNA gene amplicon sequencing library preparation and subsequently for pyro sequencing. The data summarised in Table 1 and 2 indicate that there is great variation in sequence reads and observed species among different sampling groups, and thermal processing can alter the species richness to a considerable level.

\section{Effect of thermal processing}

The samples were divided into two different categories according to the diets fed to the BSFL, and processed individually. 


\section{Microbial diversity of BSFL raised on soybean curd residues}

The microbiota observed in BSFL differed in the groups raised on SCR before and after thermal processing. Using $C$ as a control to assess the microbial differences, the results revealed that the overall microbial community structure was very closely associated with the effects of different heat treatments. The main effect and the interactive effects were also observed on the microbial members. The microbiota analysis indicated that a total of 321,052 sequence reads were observed from all samples of the BSFL raised on SCR with an average of 53,508 $\pm 12,399$ reads per sample. Whereas, the number of observed species, Chao1 (species richness index) as well as the Shannon diversity index varied between different groups as indicated by Table 1 and Figure 1 , which may be the result of heat treatments.
When the OTUs are considered from the phylum up to the genus level, a high microbial diversity has been observed with 4 phyla, 47 class, 93 order, 152 families, and 286 genera. The microbiota analysis showed that taxa at the phylum level were dominated by Proteobacteria, Bacteroidetes, Firmicutes and Actinobacteria (Figure 2 and Figure 3).

Furthermore, using $C$ group to assess the effect of heat treatments, we found that thermal processing significantly contributed to and showed the changes in the microbial structure as observed in the former group; the ratio of Firmicutes was significantly increased in OD5 group, which accounts for $63 \%$ of the total bacterial communities observed in the samples. However, the abundance of Bacteroidetes was significantly reduced in OD22 (37\%), MD5 (28\%) and OD5 (15\%) as compared to C and FD groups. A slight change in the abundance of Proteobacteria

Table 1. Number of sequence reads per black soldier fly larvae (BSFL) sample from different groups assigned to OTUs, and alpha diversity metrics values (normalised at the lowest sample size: 32,457 reads) of BSFL fed on soybean curd residues (SCR) and controls compared with groups treated by different heat treatments.

\begin{tabular}{|c|c|c|c|c|c|c|}
\hline \multirow[t]{2}{*}{ Phylum } & \multicolumn{6}{|l|}{ Sample } \\
\hline & C.SCR & FD.SCR & MD10.SCR & OD22.SCR & MD5.SCR & OD5.SCR \\
\hline Proteobacteria & 6,873 & 9,865 & 17,737 & 16,520 & 18,854 & 8,053 \\
\hline Firmicutes & 7,250 & 10,768 & 12,408 & 12,781 & 10,453 & 41,970 \\
\hline Bacteroidetes & 15,345 & 26,974 & 22,962 & 19,728 & 10,606 & 9,792 \\
\hline Actinobacteria & 2,533 & 8,965 & 8,427 & 6,538 & 3,354 & 5,481 \\
\hline RsaHF231 & 147 & 352 & 615 & 525 & - & 737 \\
\hline Tenericutes & 143 & 170 & 286 & 167 & 11 & 96 \\
\hline Deinococcus-Thermus & 4 & 2 & 1 & 1 & - & 1 \\
\hline Acidobacteria & 64 & 2 & 1 & 1 & - & 109 \\
\hline Chloroflexi & 34 & - & - & - & - & 35 \\
\hline Cyanobacteria & 17 & 5 & - & - & - & 81 \\
\hline Fusobacteria & - & 2 & 1 & 2 & 16 & - \\
\hline Oxyphotobacteria & - & 0 & - & - & 12 & 59 \\
\hline Nitrospirae & 14 & 1 & - & - & - & 5 \\
\hline Planctomycetes & 12 & - & - & - & - & 26 \\
\hline Verrucomicrobia & 3 & 1 & 1 & 1 & 4 & 8 \\
\hline Deferribacteres & - & 22 & - & - & - & - \\
\hline Gemmatimonadetes & 4 & - & - & - & - & - \\
\hline Spirochaetes & - & 1 & - & - & - & 10 \\
\hline Euryarchaeota & - & - & - & - & 50 & - \\
\hline Thermomicrobia & 1 & - & - & - & - & - \\
\hline Marinimicrobia_.SAR406_clade & 1 & - & - & - & - & - \\
\hline Armatimonadetes & 1 & - & - & - & - & - \\
\hline Others & 11 & 6 & 15 & 23 & 2,792 & 103 \\
\hline Total reads & 32,457 & 57,136 & 62,454 & 56,287 & 46,152 & 66,566 \\
\hline Observed species & 680 & 413 & 478 & 421 & 493 & 407 \\
\hline Goods coverage & 0.997 & 0.997 & 0.996 & 0.996 & 0.998 & 0.998 \\
\hline Chao1 & 749.183 & 495.269 & 615.308 & 535.13 & 525.543 & 464.75 \\
\hline Shannon & 5.895 & 5.504 & 5.718 & 5.812 & 5.149 & 5.511 \\
\hline
\end{tabular}




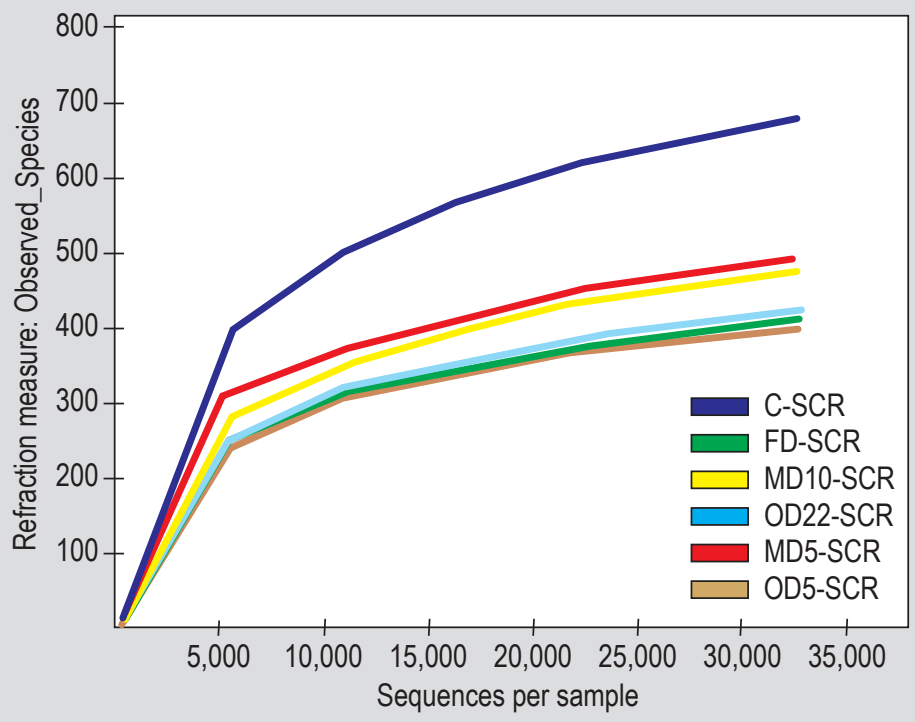

Figure 1. Refraction curve analysis of different black soldier fly larvae raised on soybean curd residues (SCR).

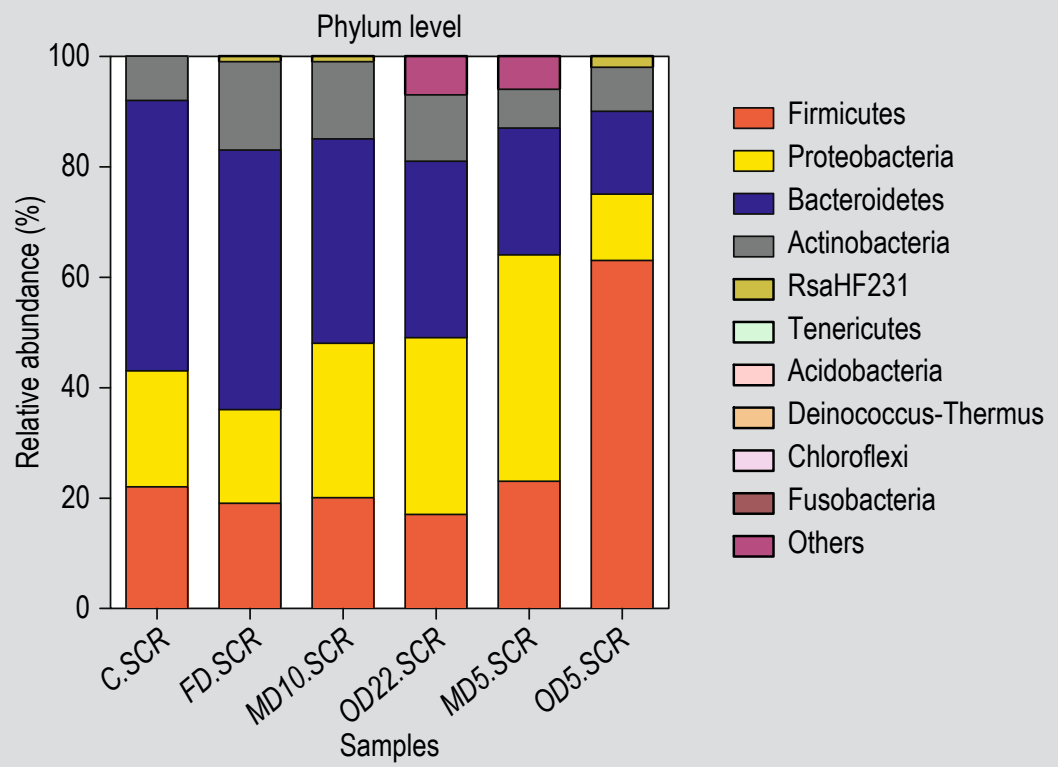

Figure 2. Relative abundance of the overall most prevalent phyla in the different experimental groups of black soldier fly larvae raised on soybean curd residues (SCR).

was also observed in different groups. The phylotypes in BSFL raised on SCR and after thermal processing indicate that taxonomic distribution of the microbial taxa from phylum to genus levels are associated with thermal processing, such as overrepresented Firmicutes and reduced Bacteroidetes in OD5 group. Furthermore, many specific abundant taxa in this group were overrepresented during different heat treatments indicating differences in the way microbial communities respond during thermal processing. The differential shifts were also noticed for the species abundance (Figure 1) and OUT level (Figure 4). The maximum number of OTUs were found in controls (224 OTUs), while the lowest was observed in FD, i.e. only 20 OTUs. The maximum number of observed species was also 680 and 407 in C and OD5 groups, respectively. These results clearly explain temperature-dependent alterations of microbiota during the thermal processing of BSFL. Furthermore, there was a minor change in the 


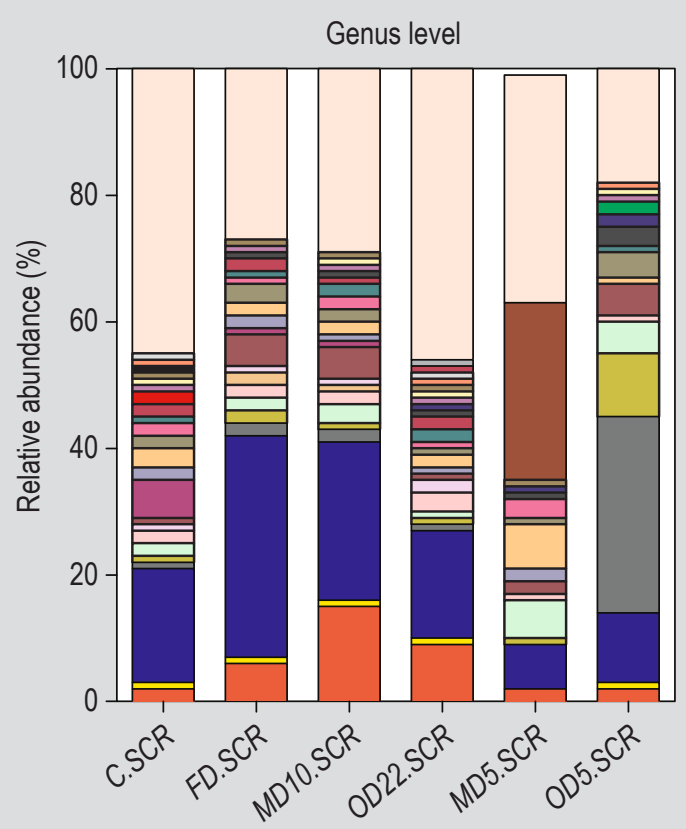

Samples

$\begin{array}{lll}\square \text { Morganella } & \square \text { Leucobacter } & \square \text { Amphibacillus } \\ \text { Sedimentibacter } & \square \text { Proteus } & \square \text { Alcaligenes } \\ \text { Dysgonomonas } & \square \text { Enterococcus } & \square \text { Vagococcus } \\ \square \text { Paenibacillus } & \square \text { Myroides } & \square \text { Pseudomonas } \\ \square \text { Brevibacillus } & \square \text { Erysipelothrix } & \square \text { Salana } \\ \square \text { Providencia } & \square \text { Campylobacter } & \square \text { Brevibacterium } \\ \square \text { Bacteroides } & \square \text { Citrobacter } & \text { Moheibacter } \\ \square \text { Desulfovibrio } & \square \text { Ureibacillus } & \square \text { Lachnoclostridium } \\ \square \text { Ignatzschineria } & \square \text { Paenalcaligenes } \square \text { Ruminococcaceae_UCG-014 } \\ \square \text { unidentified_Oxyphotobacteria } & \square \text { Lysinibacillus } \\ \square \text { Oligella } & \square \text { Bacillus } & \square \text { Acinetobacter } \\ \square \text { Klebsiella } & \square \text { Others }\end{array}$

Figure 3. Relative abundance of the overall most prevalent genera in the different experimental groups of black soldier fly larvae raised on soybean curd residues (SCR).

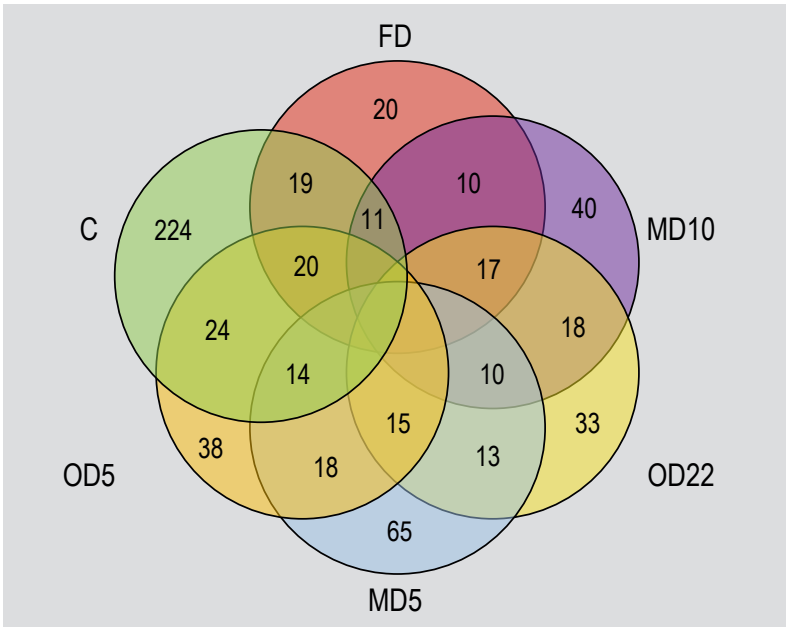

Figure 4. Venn diagram of the samples showing total OTUs observed in different soybean curd residues samples. abundance of pathogenic bacteria, with a significant increase in the abundance of Bacillus observed in OD5 group while in another group their abundance fluctuates non-significantly. However, other pathogenic bacteria, including Pseudomonas, Campylobacter, Enterococcus, were also found during all heat treatments.

\section{Effect of different heat treatments on human bacterial pathogen in BSFL raised on soybean curd residues}

The relative abundance of pathogenic bacteria in each sample represents over-all prevalence of pathogenic communities in respective samples. (Figure 5). The heat treatments have a greater effect on pathogenic bacterial community, which results in reductions in various pathogens. Paenibacillus, Bordetella, Campylobacter, Pseudomonas, and Bacillus were found in higher concentrations in C (Control), while 


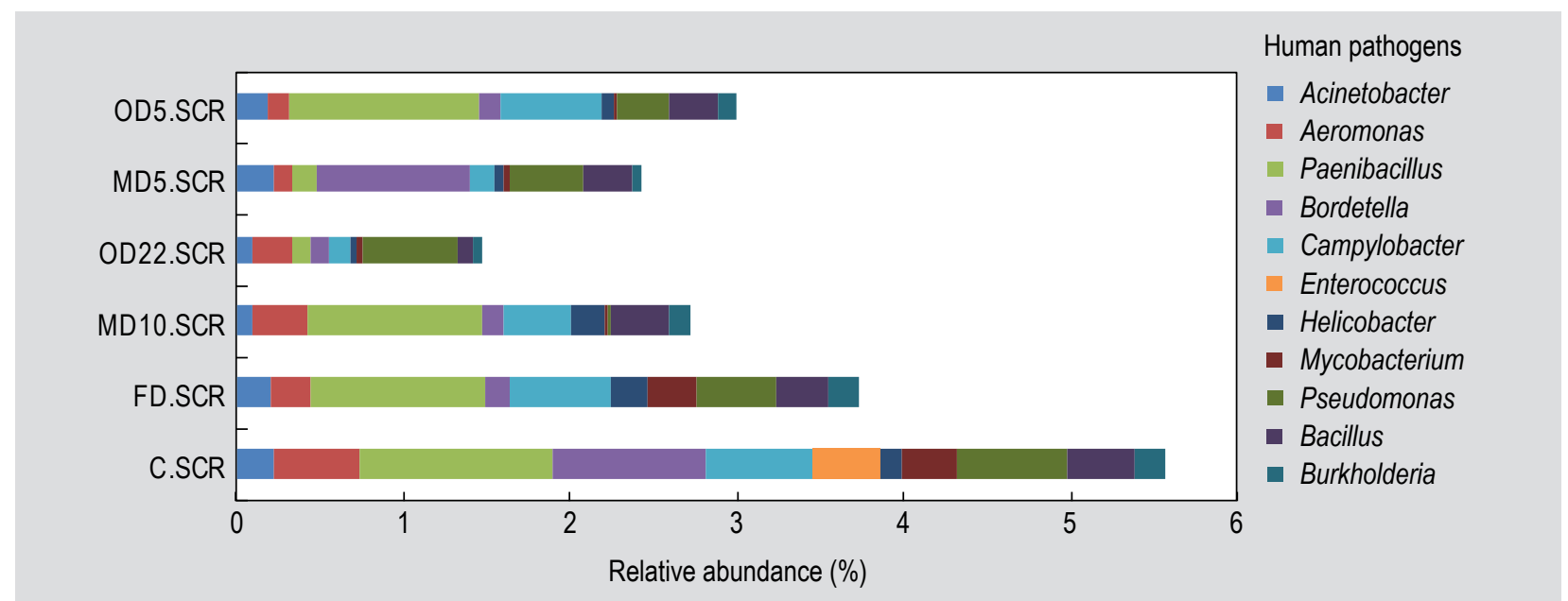

Figure 5. Relative abundance of human pathogenic bacterial communities in each sample in black soldier fly larvae developed on soybean curd residues (SCR).

different heat treatments of samples showed a decrease in pathogenic bacterial communities in all other groups. Enterococcus was found only in $\mathrm{C}$ group (control), but in heat treatment disappeared from FD, MD10, OD22, MD5 and OD5 groups. However, OD22 dried samples in oven (for 22 minutes at $150^{\circ} \mathrm{C}$ ) showed a higher decrease in pathogen community than FD, MD10, MD5 and OD5.

\section{Microbial diversity of BSFL raised on artificial feed}

In the present study, the microbial diversity of both of these groups contributed to almost similar microbial divisions, although the main and dominant taxa in each division obviously differed. It should be remembered that diet is an essential exogenous driving factor for microbial configurations. The comparison in BSFL fed on two diets with different thermal and non-thermal processing showed that the microbial diversity within the intra-species host was different, confirming the influence of diets on microbial structure and its composition. This change might be related to differences in the macro- and micronutrients of the diet ingredients. In light of these findings, we assumed that different diets might alter the microbial diversity in BSFL in terms of their quantity and composition. Therefore, we analysed the effect of AF on the microbial diversity in BSFL when AF was provided as food. Our results indicate that a total of 381,409 reads were detected from all samples with an observed species range of 460 to 562 species per sample (Figure 6). However, when compared with previous

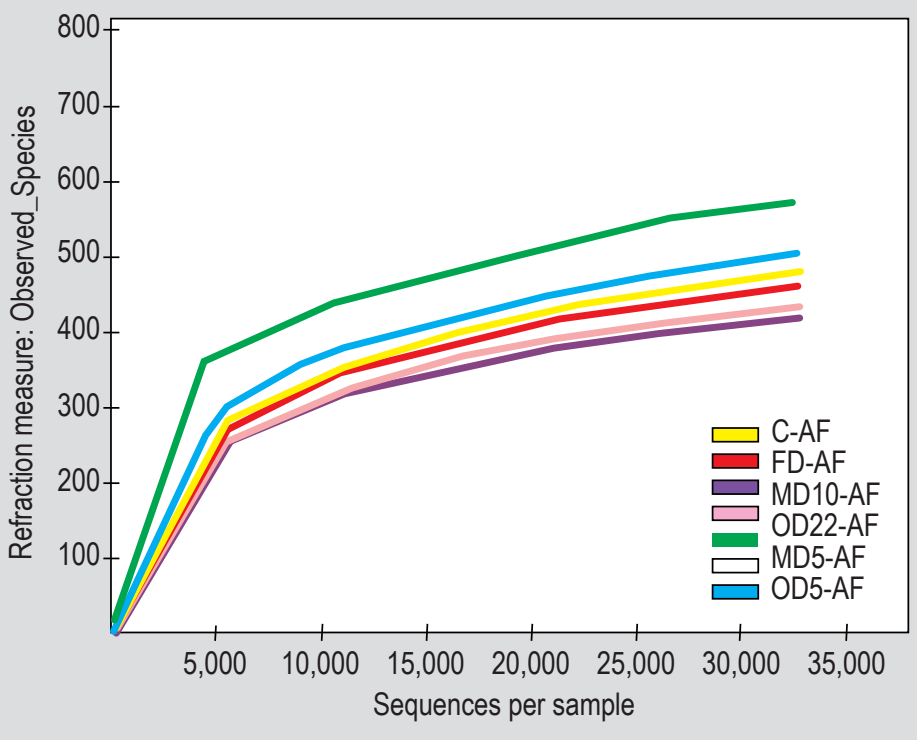

Figure 6. Refraction curve analysis of different black soldier fly larvae raised on artificial feed (AF). 
groups, BSFL raised on AF shows the lowest microbial diversity (Table 2).

When the OTUs are considered from the phylum up to the genus level, a high microbial diversity has been observed with 4 phyla, 14 classes, 38 orders, 80 families, and 273 genera. The microbiota analysis showed that taxa at the phylum level were dominated by Proteobacteria, Bacteroidetes, Firmicutes and Actinobacteria (Figure 7 and 8).

The results indicate that BSFL raised on AF is dominated by Proteobacteria when analysed for microbiota diversity; this accounts for $58 \%$ of the total bacterial diversity while the only Morganella species accounts for $48 \%$ of the total bacterial population. These bacteria are considered as a commensal within the intestine and remain as normal flora. Next to Proteobacteria, Bacteroidetes were common, comprising approx. $22 \%$ of the total bacteria population; in this group the most dominant bacteria was Dysgonomonas spp, which accounts for $12 \%$ of the total bacterial diversity. However, other bacterial groups found were Firmicutes (17\%) and Actinobacteria at only 2\%. Moreover, the other most common genera found in this group include Enterococcus, Sedimentibacter, Bacteroides, Campylobacter, Providecia, Actinomyces, and Helicobacter.
Moreover, species richness indicates that there are much fewer bacterial species found in this group than in BSFL raised on SCR enumerated with or without bacteria. The total bacterial species found in this group were far less abundant than both of the former groups (Table 2). Furthermore, only 115 OTUs were found, which is significantly lower than those of the two former groups (Figure 9). These results indicate that BSFL raised on AF have a direct effect on microbial diversity, which will be the interest of further studies. Furthermore, thermal processing of samples of BSFL fed on AF showed that there is a significant change in bacterial diversity. As observed in control samples, the highest bacterial species count belongs to Proteobacteria, but in OD22 there is a significant change in the overall abundance with a reduction up to $24 \%$ of the total bacteria population. This bacterial shift during the heat treatments results in the increased abundance of Firmicutes, with $56 \%$ of the total bacteria as compared to $17 \%$ both in $C$ and MD10. The abundance of Actinobacteria also increased along with heat treatment, as there were only $2 \%$ Actinobacteria observed in C but 6 and 7\% in both MD10 and OD22. In contrast, the abundance of Bacteroidetes also decreased with heat treatments, as there was $22 \%$ total abundance observed in $\mathrm{C}$ (control), but a significant reduction during MD10 (10 min in mild-high microwave oven), heat treatment and recorded as $17 \%$, but only $10 \%$

Table 2. Number of sequence reads per black soldier fly larvae (BSFL) sample of different groups assigned to OTUs, and alpha diversity metrics values (normalised with the total sequence reads observed in control group) of BSFL fed on artificial feed (AF) and controls compared with groups exposed to different heat treatments.

\begin{tabular}{|c|c|c|c|c|c|c|}
\hline \multirow{2}{*}{ Phylum } & \multicolumn{6}{|l|}{ Sample } \\
\hline & C.AF & FD.AF & MD10.AF & OD22.AF & MD5.AF & OD5.AF \\
\hline Proteobacteria & 36,589 & 39,564 & 42,402 & 18,063 & 17,737 & 15,343 \\
\hline Firmicutes & 10,839 & 11,233 & 12,168 & 42,230 & 12,228 & 13,544 \\
\hline Bacteroidetes & 13,673 & 12,242 & 12,162 & 7,461 & 9,665 & 8,754 \\
\hline Actinobacteria & 1,199 & 22,344 & 4,434 & 5,338 & 2,130 & 3,498 \\
\hline RsaHF231 & 207 & 278 & 325 & 1,214 & 0 & 0 \\
\hline Tenericutes & 438 & 345 & 171 & 268 & 0 & 0 \\
\hline Deinococcus-Thermus & 4 & 2 & 9 & 196 & 0 & 0 \\
\hline Acidobacteria & 1 & 2 & 2 & 3 & 0 & 0 \\
\hline Cyanobacteria & 4 & 3 & 0 & 10 & 0 & 0 \\
\hline Fusobacteria & 0 & 0 & 0 & 0 & 25 & 0 \\
\hline Nitrospirae & 0 & 0 & 0 & 3 & 0 & 0 \\
\hline Verrucomicrobia & 9 & 0 & 1 & 25 & 2 & 1 \\
\hline Lentisphaerae & 0 & 0 & 0 & 1 & 0 & 9 \\
\hline Others & 32 & 22 & 11 & 53 & 2848 & 45 \\
\hline Total reads & 62,995 & 86,035 & 71,685 & 74,865 & 4,4635 & 4,1194 \\
\hline Observed species & 460 & 434 & 422 & 429 & 562 & 498 \\
\hline Goods coverage & 0.997 & 0.997 & 0.997 & 0.997 & 0.998 & 0.997 \\
\hline Chao1 & 557.278 & 517.256 & 474.354 & 492.161 & 589.243 & 498.23 \\
\hline Shannon & 4.311 & 4.231 & 4.667 & 4.555 & 5.686 & 5.111 \\
\hline
\end{tabular}




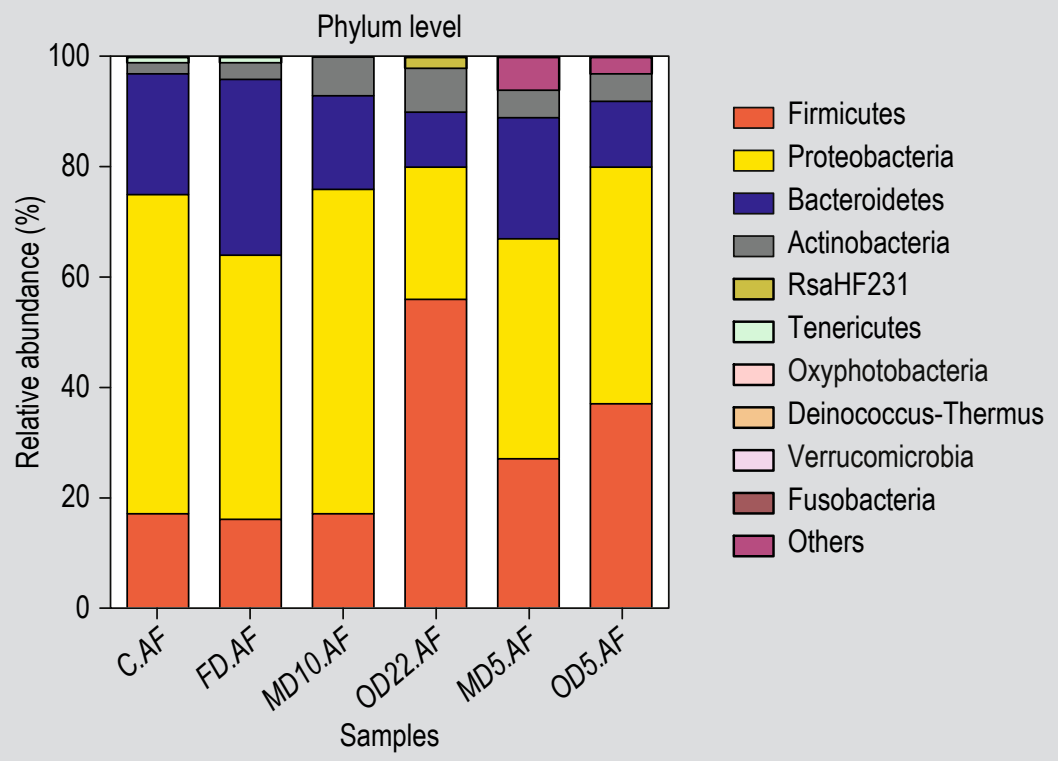

Figure 7. Relative abundance of the overall most prevalent phyla in the different experimental groups of black soldier fly larvae raised on artificial feed (AF).

recorded in OD22 (22 $\mathrm{min}$ in $150^{\circ} \mathrm{C}$ oven). However, total OTUs were slightly differently compared to the trends observed in both of the former groups. There were 42 and 57 OTUs recorded in MD10 and OD22, respectively. Furthermore, the pathogenic bacteria found in these groups were Bacillus, Campylobacter, Pseudomonas, Helicobacter, and Enterococcus.

\section{Effect of different heat treatments on the human bacterial pathogen in BSFL raised on artificial feed}

The relative abundance of human pathogenic bacteria represents an overall prevalence of pathogenic communities in respective samples. The human bacterial pathogen in BSFL showed a higher difference in each treatment as compared to control (C) (Figure 10). Campylobacter, Paenibacillus, Pseudomonas, Bordetella, and Bacillus were found higher in the control group (C). Higher reductions of human pathogens were found in the OD22 group compared to FD, MD10, MD5, and OD5. Moreover, Staphylococcus was found in $\mathrm{C}$ sample but removed after heat treatments from all respective groups. These data indicate that heat treatments have a significant influence on the pathogenic bacterial communities.

\section{Discussion}

Microbial diversity in food items is considered a major health concern as it directly affects human health; therefore, the indicators used to analyse microbial diversity play a key role in safe food production. Since the increase in demand for sources of protein contrasts sharply with the decrease in availability, insects have been considered as an alternative to fulfil animal as well as human dietary requirements. Several insect species are already widely used as a protein source in the animal production chain, but increasing demand has also attracted interest in using insects as a protein source for human consumption. For hygienic food production, the microbial diversity in such protein sources is considered a major quality control indicator as these bacterial communities can be pathogenic in nature.

Recently, BSFL have been considered for use as a protein source (Henry et al., 2015; Wang et al., 2017; Wynants et al., 2018). Similar to other insect species, BSFL can be highly contaminated with several bacterial communities including food pathogens, spoilage organisms that are considered a major health concern and quality control problem in food products (De Smet et al., 2018; Jeon et al., 2011; Wynants et al., 2018). Generally, BSFL are cultivated in a feed medium consisting of soybean, wheat bran and organic waste material (Jeon et al., 2011). These dietary resources can seriously affect the growth and production of BSFL for the production of dietary protein sources but the microbial communities within BSFL, including pathogenic as well as commensal microbiota can also be seriously affected (Zheng et al., 2013). To gain more insight into the bacterial community composition of BSFL raised on different dietary resources, we analysed all the BSFL samples using 454 pyrosequencing. As growing insect larva are thought to harbour several bacterial communities, we analysed the effect of different heat treatments on microbial diversity when BSFL are raised on different dietary sources.

The results showed that thermal processing of BSFL using different heat treatments effectively results in a reduced and 

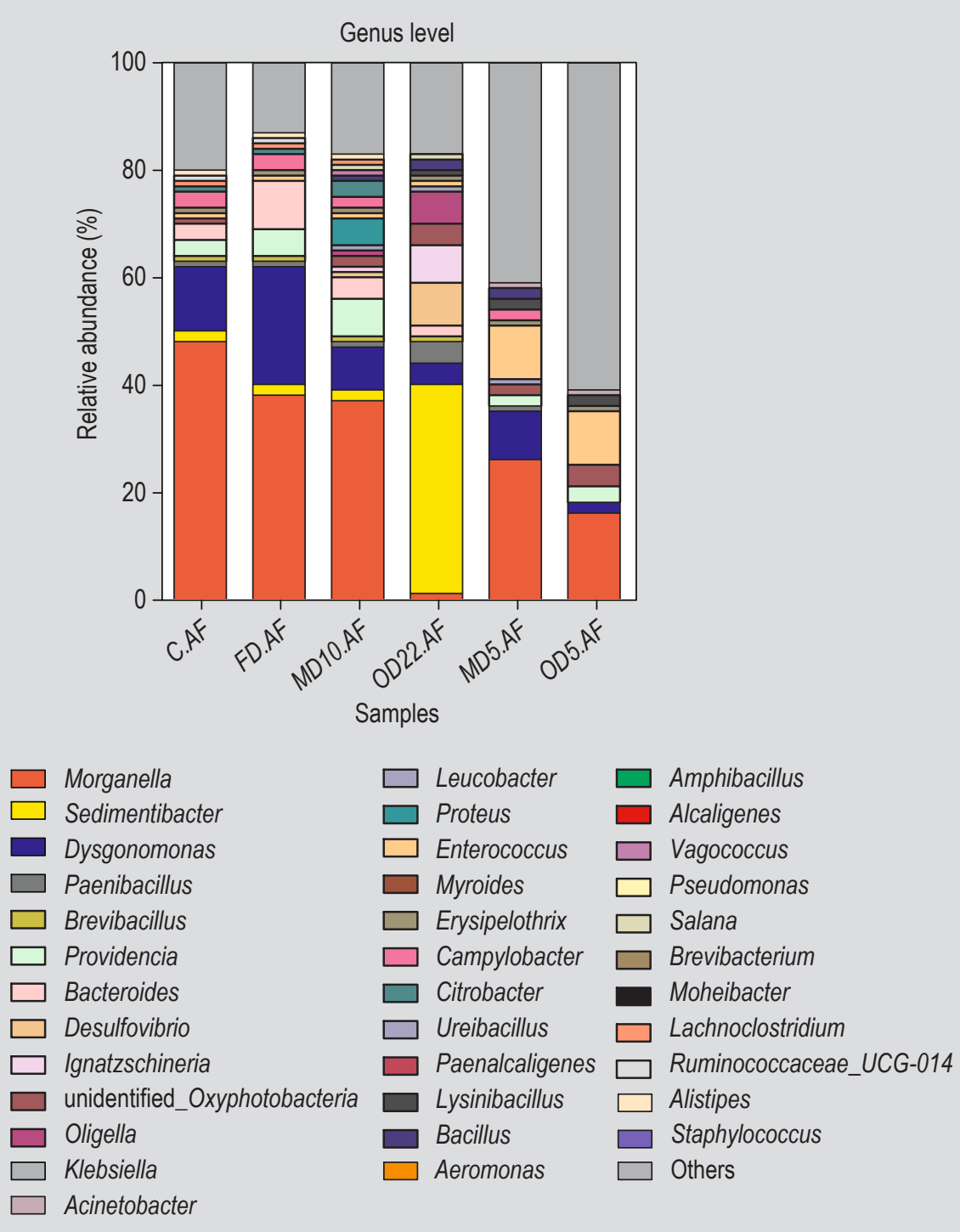

Figure 8. Relative abundance of the overall most prevalent genera in the different experimental groups of black soldier fly larvae raised on artificial feed (AF).

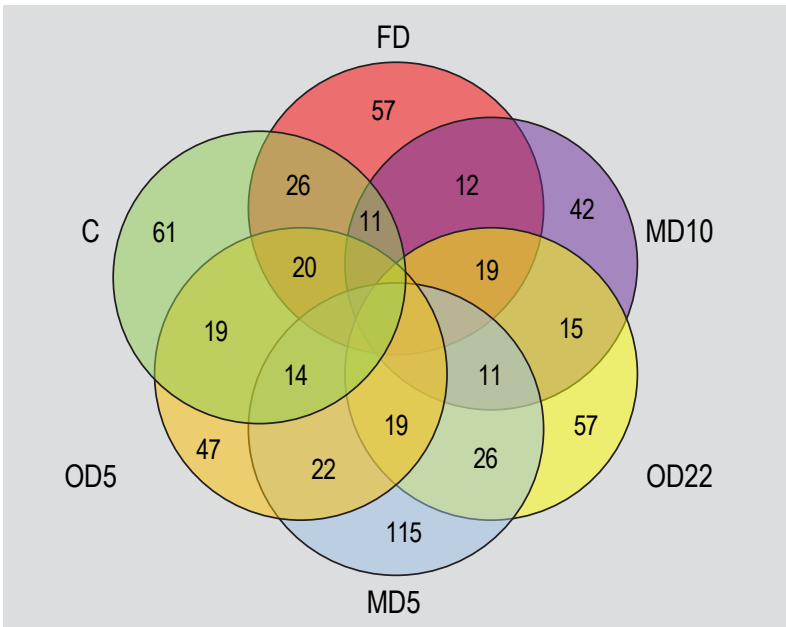

Figure 9. Venn diagram of the samples showing total OTUs observed in different samples of black soldier fly larvae raised on artificial feed. altered microbiota of BSFL raised on SCR and the other groups raised only on AF. Thermal processing significantly affected gut microbial communities, with extensively distinct responses to different heat treatments and different diets and this directly affects the quality of BSFL used as dietary purposes in the sense of microbial ecology which in turns affects the health of animals consuming BSFL as a feed source. The findings demonstrate our hypothesis that the thermal processing of BSFL drives the assembly of complex microbiota in the BSFL which may be used for dietary purpose in animal feed. However, the gut microbial communities are greatly regulated by the different food sources on which BSFLs are raised.

The BSFL fed on these different diets harbour diverse bacterial communities, predominantly Firmicutes, Proteobacteria, Bacteroidetes and Actinobacteria with small percentages of some other bacteria. These dominant phyla 


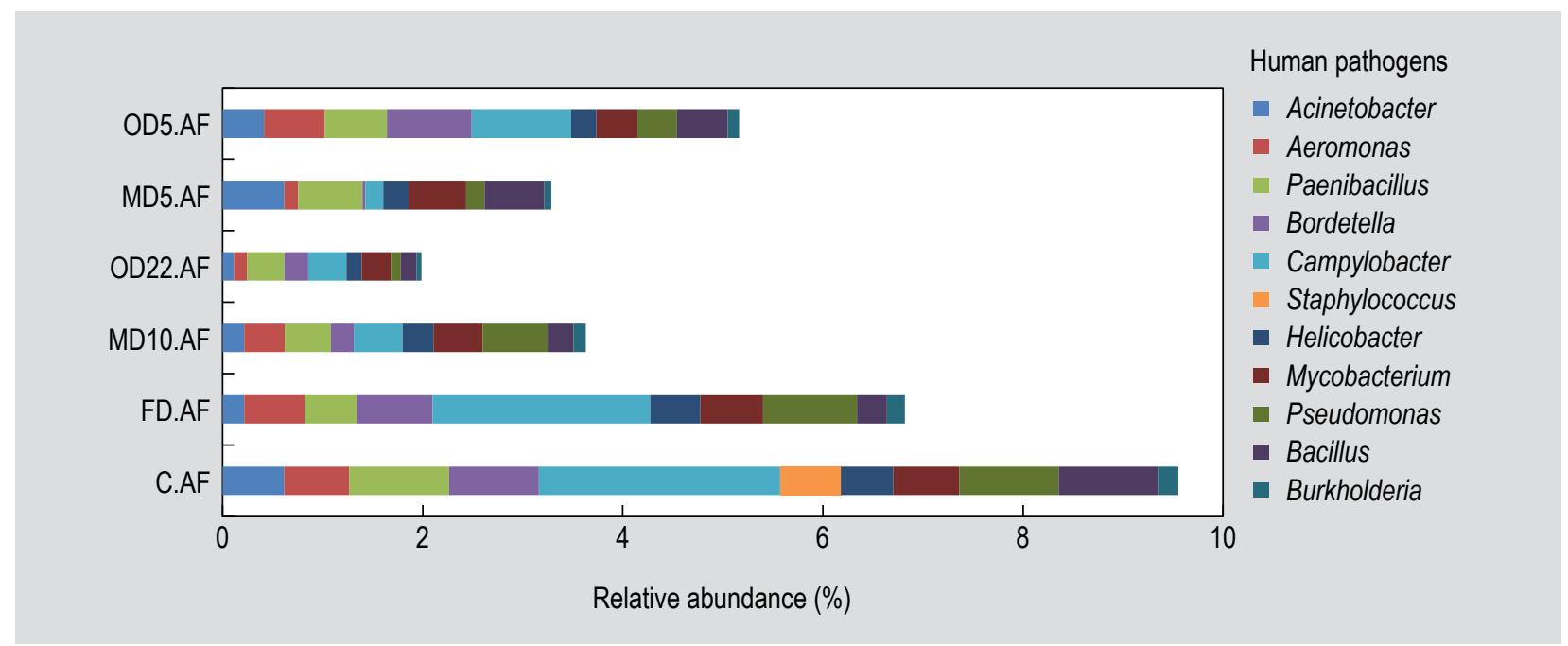

Figure 10. Relative abundance of human pathogenic bacterial communities in each sample in black soldier fly larvae developed on artificial feed (AF).

are known inhabitants of the gut of many insect species (Colman et al., 2012; De Smet et al., 2018; Jeon et al., 2011; Wynants et al., 2018), and are considered a commensal, which may provide beneficial services to their hosts (Engel and Moran, 2013). The present study reports the microbial diversity data in BSFL raised on different dietary sources and the effect of some non-pathogenic highly productive bacteria, which will shed further light on the usage of BSFL as a dietary protein source.

As observed by different researchers, insect gut microbial communities are largely dependent on carbohydrate, protein and fibre contents (Bruno et al., 2019; Jeon et al., 2011). The data indicates the significant effect of different diets and thermal processing on microbial communities, with BSFL raised on SCR showing the highest prevalence of Bacteroidetes (49\%) as compared to other groups, while AF-raised BSFL showed the highest prevalence of Proteobacteria (58\%) compared to the other taxa (Table 3). A similar phenomenon was also observed by Bruno et al. (2019), with increased levels of Bacteroidetes taxa in the midgut of BSFL fed on vegetables and standard diet, which is an indication of higher counts of this taxa as glycan degraders. In our analysis, Bacteroidetes (in particular Dysgonomonas) were the dominant taxa in the SCR-fed group, as this diet contains higher levels of fibre compared to $\mathrm{AF}$, and these bacteria may play a role in degrading fibre contents in the midgut of BSFL. On the other hand, BSFL raised on AF showed increased levels of Proteobacteria, with Morganella being dominant, among others; this is similar to the phenomenon observed in BSFL raised on a fish diet (Bruno et al., 2019). However, the detailed mechanism behind the microbial diversity still needs to be defined.
The number of OTUs observed pre- and post-thermal treatment showed an overall decrease in the unique OTU count with a decrease in the observed species number, although sequence reads vary among different samples and dietary groups. The results indicate that the BSFL raised on SCR showed a linear trend in the observed species number and OTU count being the highest species richness with higher OTUs in fresh (C) samples without heat treatments; however, a decrease in species number along with OTU count shows a direct relationship with heat treatment. While the BSFL raised on AF shows a variation in bacterial communities when compared with the former group with little fluctuation in the diversity among treatment groups, but shows an overall variation in the communities as observed when BSFL is raised on SCR. These observations clearly indicated that BSFL raised on different diets exhibits differential bacterial composition, and that these communities are also affected by the presence of bacteria. The variation in the microbial composition between the different groups is probably due to the effect of diet rather than the host physiological pressures. However, the identification of the microbiota that are common for all diet groups with the presence of certain OTUs within and between the two groups, indicates not only that diet shapes the microbial community structure of BSFL but also that these communities are affected by the presence of symbiotic bacteria.

Morganella genus was one of the most common bacteria found in the majority of the groups observed; it is believed to be a commensal in the digestive system of large animals and insects, and is considered an opportunistic pathogen (Ramya et al., 2016; Salas et al., 2017). In addition to this very prevalent bacteria, similar finding were also reported from the previous study conducted on BSFL showing the possible presence of genera Enterococcus, Pseudomonas 
Table 3. Microbiota composition of Hermetia illucens larvae of the present work in comparison with previous studies.

\begin{tabular}{|c|c|c|c|c|}
\hline Source & Sample & Feeding substrate & Major phyla & $\%$ \\
\hline \multirow[t]{9}{*}{ Present study } & Whole larvae & Soybean curd residues & Bacteroidetes & 49 \\
\hline & & & Firmicutes & 22 \\
\hline & & & Proteobacteria & 21 \\
\hline & & & Actinobacteria & 8 \\
\hline & & Artificial diet & Proteobacteria & 58 \\
\hline & & & Bacteroidetes & 22 \\
\hline & & & Firmicutes & 17 \\
\hline & & & Actinobacteria & 2 \\
\hline & & & Others & 1 \\
\hline \multirow[t]{12}{*}{ Jeon et al. (2011) } & Larval gut & Food waste & Bacteroidetes & 67.4 \\
\hline & & & Proteobacteria & 18.9 \\
\hline & & & Firmicutes & 9.4 \\
\hline & & & Fusobacteria & 2 \\
\hline & & & Actinobacteria & 1.9 \\
\hline & & Cooked rice & Proteobacteria & 54 \\
\hline & & & Firmicutes & 47.3 \\
\hline & & & Unclassified & 3.5 \\
\hline & & Calf forage & Proteobacteria & 31.1 \\
\hline & & & Actinobacteria & 24.6 \\
\hline & & & Firmicutes & 23.5 \\
\hline & & & Bacteroidetes & 20.5 \\
\hline \multirow[t]{4}{*}{ Zheng et al. (2013) } & Whole larvae & Gainesville diet & Bacteroidetes & 54.4 \\
\hline & & & Firmicutes & 20 \\
\hline & & & Proteobacteria & 16 \\
\hline & & & Actinobacteria & 9 \\
\hline \multirow[t]{10}{*}{ Bruno et al. (2019) } & Larval midgut & Standard diet & Bacteroidetes & 41.5 \\
\hline & & & Proteobacteria & 28.2 \\
\hline & & & Firmicutes & 13.6 \\
\hline & & & Actinobacteria & 3.9 \\
\hline & & Vegetable mix & Bacteroidetes & 65.4 \\
\hline & & & Proteobacteria & 19.1 \\
\hline & & & Firmicutes & 15.7 \\
\hline & & & Actinobacteria & 11.6 \\
\hline & & Fish diet & Proteobacteria & 55.5 \\
\hline & & & Firmicutes & 43 \\
\hline
\end{tabular}

and Providencia, as well as certain Bacillaceae sp. which are considered part of a microbial community often recurring in BSF larvae, regardless of different diets or other rearing conditions (Wynants et al., 2018). Lactic acid bacteria are also known to stimulate anti-inflammatory signals, and thus can be used as probiotics for the treatment and improvement of growth performance (Balcazar et al., 2007; Navarrete et al., 2013). In the present study, we also found several OTUs associated with lactic acid bacteria, including Lactobacillus, Vagococcus, and Weissella sp.

There is an abundance of some important OTUs that were hardly present in the feeds (below $2 \%$ ), such as Aeromonas sp. and Pseudomonas sp., which still vary among different samples and can serve as a pathogen when BSFL are used for dietary purposes. Those organisms were probably able to grow inside the larval gut and were subsequently excreted in high numbers into the substrate. Likewise, the decrease in bacterial diversity and the increase in abundance of a few OTUs in the larvae may be attributed to the competitive advantage of some species in the gut environment. Furthermore, the lactic acid-producing bacteria observed were represented to a large extent by Enterococcus sp. In most of the samples, this genus has already been reported in yellow mealworms and BSF (Garofalo, 2017; Jung et al., 2014; Li et al., 2015; Wynants et al., 2018). Along with some beneficial bacteria, some pathogenic bacterial communities were also observed, 
including Pseudomonas, which is common spoilagecausing bacteria for food products including milk, meat, etc (Masson et al., 2002; Stoops et al., 2012). Another member of the Enterobacteriaceae family, Klebsiella sp. was also found in great abundance, especially in bran and soybean enumerated with Lactobacillus buchneri. This genus has been isolated from different natural environments including several food items and is considered a pathogen causing several diseases and food poisoning (William and Leber, 2018).

Fresh insects are highly toxic and are contaminated with various spoilage microorganisms and food pathogens (Stoops et al., 2016). The present study showed that fresh BSFL was contaminated with different human pathogens. Similar investigations were reported in mealworm larvae (Tenebrio molitor) and grasshoppers (Locusta migratoria migratorioides) in the previous study by (Stoops et al., 2016). Moreover, in the current investigation Enterococcus was found only with the SCR diet while Staphylococcus was discovered with the AF diet. Both pathogens were removed from all groups after heat treatments. Group OD22, samples dried in an oven for $22 \mathrm{~min}$ at $150^{\circ} \mathrm{C}$, showed a significant effect on microbial communities when compared to all heat treatments. A heating step (boiling for $10 \mathrm{~min}$ ) is sufficient for the inactivation of Enterobacteriaceae in insects, but some bacterial endospores may survive this treatment (Rumpold and Schlüter, 2013). Although the use of antibiotics in insect-rearing should not be encouraged, the finding at least demonstrates that the microbial load on reared insects can be controlled.

\section{Conclusion}

In conclusion, the present study of microbial community structure - BSFL raised on different diets with the effect of symbiotic bacteria on the bacterial composition - is the first in-depth NGS study of insects used as an alternative protein source. The taxonomic information collected in the present study will be of great interest in defining the healthy use of edible protein obtained from insects to combat increasing demands for protein. The determination of taxonomic information along with the presence of beneficial as well as pathogenic bacteria used as an indicator could also be used in the future to monitor the production of healthy food. From the results, it is clear that the main differences in bacterial composition of BSFL, both in abundance and diversity, occur as a result of rearing on different dietary sources. Furthermore, heat treatments have a greater effect on the human pathogenic bacterial community with a reduction in the pathogens. Enterococcus was found in BSFL raised on the SCR diet, while Staphylococcus was found in AF but could not be detected after heat treatments in any of the groups. The heat-treated samples of BSFL reared on SCR, and AF (Group OD22 samples dried in oven, 22 min at $150{ }^{\circ} \mathrm{C}$ ), had a better effect on the bacterial community than all heat treatments. Next-generation high throughput sequencing studies investigating the microbiome of BSFL are of great importance for understanding and defining the shifts of bacterial diversity in the production of hygienic food and feed.

\section{Acknowledgements}

This work was supported by the National Key Technology R \& D Program of China (2018YFD0500203 and 2017YFD0800200) and China's special Fund for AgroScientific Research in Public and Agriculture Research, China (201303094).

\section{Conflict of interest}

The authors declare no conflict of interest.

\section{References}

Balcázar, J.L., De Blas I, R.I., Vendrell, D., Gironés, O. and Muzquiz, J.L., 2007. Enhancement of the immune response and protection induced by probiotic lactic acid bacteria against furuncolosis in rainbow trout (Oncorhynchus mykiss), FEMS Immunology and Medical Microbiology 51: 185-193.

Barnett, J., Begen, F., Howes, S., Regan, A., McConnon, A. and Marcu, A., 2016. Consumers' confidence, reflections and response strategies following the horsemeat incident. Food Control 59: 721-730. https:// doi.org/10.1016/j.foodcont.2015.06

Barson, W.J. and Leber, A., 2018. Klebsiella and Raoultella species. In: Long, S.S., Prober, C.G. and Fischer, M. (eds.) Principles and practice of pediatric infectious diseases $\left(5^{\text {th }}\right.$ Ed.). Elsevier, Milton, ON, Canada.

Belluco, S., Losasso, C., Maggioletti, A.C.C., Paoletti, M.G. and Ricci., A., 2013. Edible insects in a food safety and nutritional perspective: a critical review. Comprehensive Review in Food Science and Food Safety 12: 296-313.

Bruno, D., Bonelli, M., De Filippis, F., Lelio, I.D., Tettamanti, G., Casartelli, M., Ercolini, D. and Caccia, S., 2019. The intestinal microbiota of Hermetia illucens larvae is affected by diet and shows a diverse composition in the different midgut regions. Applied and Environmental Microbiology 85: e01864-18.

Cai, M., Ma, S., Hu, R., Tomberlin, J.K,. Thomashow, L.S., Zheng, L., Li, W., Yu, Z. and Zhang, J., 2018a. Rapidly mitigating antibiotic resistant risks in chicken manure by Hermetia illucens bioconversion with intestinal microflora. Environmental Microbiology 20: 40514062. https://doi.org/10.1111/1462-2920.14450

Cai, M., Ma, S., Hu, R., Tomberlin, J.K., Yu, C., Huang, Y., Zhan, S., Li, W., Zheng, L., Yu, Z. and Zhang, J., 2018b. Systematic characterization and proposed pathway of tetracycline degradation in solid waste treatment by Hermetia illucens with intestinal microbiota. Environmental Pollution 242: 634-642. https://doi. org/10.1016/j.envpol.2018.06.105 
Campbell, M., Ortuño. J., Stratakos. A.C., Linton, M., Corcionivoschi, N., Elliott, T., Koidis, A. and Theodoridou, K., 2020. Impact of thermal and high-pressure treatments on the microbiological quality and in vitro digestibility of black soldier fly (Hermetia illucens) larvae. Animals 10: 682.

Caparros Megido, R., Poelaert, C., Ernens, M., Liotta, M., Blecker, C., Danthine, S., Tyteca, E., Haubruge, É., Alabi, T., Bindelle, J. and Francis, F., 2018. Effect of household cooking techniques on the microbiological load and the nutritional quality of mealworms (Tenebrio molitor L. 1758). Food Research International 106: 503508.

Charlton, A.J., Dickinson, M., Wakefield, M.E., Fitches, E., Kenis, M., Han, R., Zhu, F., Kone, N., Grant, M., Devic, E., Bruggeman, R., Prior and Smith, R., 2015. Exploring the chemical safety of fly larvae as a source of protein for animal feed. Journal of Insects as Food and Feed 1: 7-16.

Chen, B., Teh, B.S., Sun, C., Chao, S., Sirui, H., Xingmeng, L., Wilhelm, B. and Yongqi Shaoa, Y., 2016. Biodiversity and activity of the gut microbiota across the life history of the insect herbivore Spodoptera littoralis. Scientific Reports 6: 1-14.

Colman, D.R., Toolson, E.C. and Takacs-Vesbach, C.D., 2012. Do diet and taxonomy influence insect gut bacterial communities? Molecular Ecology 21: 5124-5137

Delicato, C., Joachim, J.S., Koen, D., Xavier, G. and Tzompa-Sosa, D.A., 2020. Consumers' perception of bakery products with insect fat as partial butter replacement. Food Quality and Preference 79: 103755.

De Smet, J., Wynants, E., Cos, P. and Van Campenhout, L., 2018. Microbial community dynamics during rearing of black soldier fly larvae (Hermetia illucens) and impact on exploitation potential. Applied and Environmental Microbiology 8: 2722-2717.

Engel, P. and Moran, N.A., 2013. The gut microbiota of insect's e diversity in structure and function. FEMS Microbiology Reviews 37: 699-735.

Ercolini, D., 2013. High-throughput sequencing and metagenomics: moving forward in the culture-independent analysis of food microbial ecology. Applied Environmental Microbiology 79: 31483155.

Garofalo, C., Andrea, O., Vesna, M., Manuela, T., Federica, C., Lucia A., Paola, R., Sara, R. and Nunzio, I., 2017. The microbiota of marketed processed edible insects as revealed by high-throughput sequencing. Food Microbiology 62: 15-22.

Haynes, E., Elisa, J., Miguel, A.P. and Sarah, J.H., 2019.The future of NGS (next generation sequencing) analysis in testing food authenticity. Food Control 101: 134-143.

Henry, M., Gasco, L., Piccolo, G. and Fountoulaki, E., 2015. Review on the use of insects in the diet of farmed fish: past and future. Animal Feed Science and Technology 203: 1-22.

Hernandez-Flores, L., Llanderal-Cazares, C., Guzman-Franco, A.W. and Aranda-Ocampo, S., 2015. Bacteria present in Comadia redtenbacheri larvae (Lepidoptera: Cossidae). Journal of Medical Entomology 52: 1150-1158.

Jeon, H., Park, S., Choi, J., Jeong, G., Lee, S., Choi, Y. and Lee, S., 2011. The intestinal bacterial community in the food waste-reducing larvae of Hermetia illucens. Current Microbiology 62: 1390-1399.
Jung, J., Heo, A., Park, Y.W., Kim, Y.J., Koh, H. and Park, W., 2014. Gut microbiota of Tenebrio molitor and their response to environmental change. Journal of Microbiology and Biotechnology 24: 888-897.

Klunder, H.C., Wolkers-Rooijackers, J., Korpela, J.M. and Nout, M.J.R., 2012. Microbiological aspects of processing and storage of edible insects. Food Control 26: 628-631.

Kubo, M.T.K., Érica, S.S., Eduardo, S.F., Pedro, E.D.A., Sébastien, C., Lionel, B., Sudhir, K.S. and Gut, J.A.W., 2020. Non-thermal effects of microwave and ohmic processing on microbial and enzyme inactivation: a critical review. Current Opinion in Food Science, https://doi.org/10.1016/j.cofs.2020.01.004

Lalander, C., Diener, S., Zurbrügg, C. and Vinnerås, B., 2019. Effects of feedstock on larval development and process efficiency in waste treatment with black soldier fly (Hermetia illucens). Cleaner Production 208: 211-219.

Liavata, B., García-Pérez, J.V., Simal, S. and Cárcel, J.A., 2019. Innovative pre-treatments to enhance food drying: a current review. Current Opinion in Food Science 35: 20-26. https://doi. org/10.1016/j.cofs.2019.12.001

Li, W., Li, M., Zheng, L., Liu, Y., Zhang, Y., Yu, Z., Ma, Z. and Li, Q., 2015. Simultaneous utilization of glucose and xylose for lipid accumulation in black soldier fly. Biotechnology for Biofuels 8: 1-6.

Masson, Y., Ainsworth, P., Fuller, D., Bozkurt, H. and Ibanoglu, S., 2002. Growth of Pseudomonas fluorescens and Candida sake in homogenized mushrooms under modified atmosphere. Journal Food Engineering 54: 125-131.

Navarrete, P., Fuentes, P.D., Fuente, L., Barros, L., Magne, L., Opazo, F., Ibacache, R., Espejo, C. and Romero, R., 2013. Short-term effects of dietary SBM and lactic acid bacteria on intestinal morphology and microbiota of Atlantic salmon. Aquaculture Nutrition 19: 827-836.

Oonincx, D.G.A.B. and De Boer, I.J.M., 2012. Environmental impact of the production of mealworms as a protein source for humans - a life cycle assessment. PLoS ONE 7: e51145.

Opara, M.N., Sanyigha, F.T., Ogbuewu, I.P. and Okoli, I.C., 2012. Studies on the production trend and quality characteristics of palm grubs in the tropical rainforest zone of Nigeria. Journal of Agricultural Technology 8: 851-860.

Ramya, S.L., Venkatesan, T., Srinivasa, M.K., Jalali, S.K. and Verghese, A., 2016. Detection of carboxylesterase and esterase activity in culturable gut bacterial flora isolated from diamondback moth, Plutella xylostella (Linnaeus), from India and its possible role in indoxacarb degradation. Brazilian Journal of Microbiology 47: 327-336.

Rehman, K., Cai, M., Xiao, X., Zheng, L., Wang, H., Soomro, A.A., Zhou, Y., Li, W., Yu, Z. and Zhang, J., 2017b. Cellulose decomposition and larval biomass production from the co-digestion of dairy manure and chicken manure by mini-livestock (Hermetia illucens L.). Journal Environmental Management 196: 458-465.

Rehman, K., Rehman, R., Somroo, A.A., Cai, M., Zhenga, L., Xiao, X., Rehman, A., Rehman, A., Tomberlin, J.K., Yu, Z. and Jibin, Z., 2019. Enhanced bioconversion of dairy and chicken manure by the interaction of exogenous bacteria and black soldier fly larvae. Environmental Management 237: 75-83.

Rumpold, B.A. and Schlüter, O.K., 2013. Nutritional composition and safety aspects of edible insects. Molecular Nutrition \& Food Research 57(5): 802-823. https://doi.org/10.1002/mnfr.201200735 
Rumpold, B.A., Fröhling, A., Reineke, K., Knorr, D., Boguslawski, S., Ehlbeck, J. and Schlüter, O., 2014. Comparison of volumetric and surface decontamination techniques for innovative processing of mealworm larvae (Tenebrio molitor). Innovative Food Science and Emerging Technologies 26: 232-241.

Salas, B., Conway, H.E., Schuenzel, E.L., Hopperstad, K., Vitek, C. and Vacek, D.C., 2017. Morganella morganii (Enterobacteriales: Enterobacteriaceae) is a lethal pathogen of Mexican fruit fly (Diptera: Tephritidae) larvae. Florida Entomologist 100: 743-751.

Soomro, A.A., Ur Rehman, K., Zheng, L., Cai, M., Xiao, X., Hu, S., Mathys, A., Gold, M., Yu, Z. and Zhang, J., 2019. Influence of Lactobacillus buchneri on soybean curd residue co-conversion by black soldier fly larvae (Hermetia illucens) for food and feedstock production. Waste Management 86: 114-122.

Stoops, J., Claes, J., Maes, P. and Van Campenhout, L., 2012. Growth of pseudomonas fluorescens in modified atmosphere packaged tofu. Letters in Applied Microbiology 54: 195-202.

Stoops, J., Crauwels, S., Waud, M., Claes, J., Lievens, B. and Van Campenhout, L., 2016. Microbial community assessment of mealworm larvae (Tenebrio molitor) and grasshoppers (Locusta migratoria migratorioides) sold for human consumption. Food Microbiology 53: 122-127.

Sun, Z., Yahong, L., Zhang, H., Kumar, D., Liu, B., Gong, Y., Zhu, M., Zhu, L., Liang, Z., Kuang, S., Chen, F., Hu, X., Cao, G., Xue, R. and Chengliang, G., 2016. Effects of BmCPV infection on silkworm Bombyx mori intestinal bacteria. PLoS ONE 11(1): e0146313. https:// doi.org/10.1371/journal.pone.0146313
Tomberlin, J.K., Sheppard, D.C. and Joyce, J.A., 2002. Selected lifehistory traits of black soldier flies (Diptera: Stratiomyidae) reared on three artificial diets. Annals of the Entomological Society of America 95: 379-386.

Van Huis, A., 2013. Potential of insects as food and feed in assuring food security. Annual Review of Entomology 58: 563-583.

Verbeke, W., 2015. Profiling consumers who are ready to adopt insects as a meat substitute in a Western society. Food Quality and Preference 39: 147-155.

Wang, Y.S. and Shelomi, M., 2017. Review of black soldier fly (Hermetia illucens) as animal feed and human food. Foods 6(10): 91. https:// doi.org/10.3390/foods6100091

Wynants, E., Frooninckx, L., Crauwels, S., Verreth, C., De Smet, J., Sandrock, C., Wohlfahrt, J., Van Schelt, J., Depraetere, S., Lievens, B., Van Miert, S., Claes, J. and Van Campenhout, L., 2018. Assessing the microbiota of black soldier fly larvae (Hermetia illucens) reared on organic waste streams on four different locations at laboratory and large scale. Microbial Ecology 77: 913-930.

Zhang, Z. and Li, D., 2018. Thermal processing of food reduces gut microbiota diversity of the host and triggers adaptation of the microbiota: evidence from two vertebrates. Microbiome 6: 99.

Zheng, L., Hou, Y., Li, W., Yang, S., Li, Q. and Yu, Z., 2013. Exploring the potential of grease from yellow mealworm beetle (Tenebrio molitor) as a novel biodiesel feedstock. Applied Energy 101: 618-662.

Zheng, L., Li, Q. and Zhang, J., 2012. Double the biodiesel yield: rearing black soldier fly larvae, Hermetia illucens, on solid residual fraction of restaurant waste after grease extraction for biodiesel production. Renewable Energy 41: 75-79. 
